\title{
ESTIMATIVA DA QUANTIDADE DE ÁRVORES URBANAS A PARTIR DE MODELO ESTATÍSTICO E CRIAÇÃO DO ÍNDICE MENDES DE ARBORIZAÇÃO URBANA
}

\author{
ESTIMATED QUANTITY OF URBAN TREES FROM STATISTICAL MODEL AND \\ CREATION OF MENDES URBAN TREE INDEX
}

\author{
Flávio Henrique Mendes ${ }^{1}$
}

\begin{abstract}
RESUMO
As árvores urbanas são fundamentais para a resiliência das cidades. Sua gestão está condicionada às prefeituras, entretanto, muitas delas não têm conhecimento de quantas árvores existem no perímetro urbano, sendo este o ponto inicial para o manejo. $O$ objetivo desta pesquisa foi desenvolver um modelo estatístico capaz de estimar a quantidade de árvores baseado na população da cidade, criando o Índice Mendes de Arborização Urbana (IMAU), com parâmetros quantitativos e sua correspondência qualitativa. A pesquisa baseou-se em inventários de algumas prefeituras do estado de São Paulo que já dispõem de tais informações, e, em complementaridade, analisou situações reais encontradas em campo. Os resultados revelaram mediana igual a 172 árv/1000 hab. (equivalente a 6 hab./árv). Quanto à distribuição nos 645 municípios do estado, as cidades litorâneas apresentaram as menores taxas de arborização urbana, enquanto que as regiões norte e oeste do estado (segundo quadrante), constituem as mais arborizadas. Na capital São Paulo/SP, o destaque positivo foi a Zona Oeste (123,1 árv/1000 hab.) e o negativo, a Zona Leste (somente 44 árv/1000 hab.). O modelo estatístico utilizado para criar o IMAU servirá para que as prefeituras tenham condições de estimar a quantidade de árvores existentes nas calçadas e viabilizem estudos qualitativos.
\end{abstract}

Palavras-chave: Arborização urbana; IMAU; Infraestrutura verde; Inventário florestal; Prefeitura.

\begin{abstract}
Urban trees are fundamental to the resilience of cities. Its management is conditioned to city halls, however, many of them are not aware of how many trees exist in the urban perimeter, this being the starting point for management. The objective of this research was to develop a statistical model capable of estimating the number of trees based on the population of the city, creating the Mendes Urban Tree Index (MUTI), with quantitative parameters and their qualitative correspondence. The research was based on inventories of some city halls in the State of São Paulo that already have such information, and, in complementarity, analyzed real situations found in the field. The results revealed a median equal to 172 trees/1000 inhab. (equivalent to 6 inhab./tree). As for the distribution in the 645 municipalities of the State, the coastal cities presented the lowest rates of urban afforestation, while the northern and western regions of the State (second quadrant), constitute the most forested. In the capital São Paulo/SP, the positive highlight was the West Zone (123.1 trees/1000 inhab.) and the negative, the East Zone (only 44 trees/1000 inhab.). The statistical model used to create the MUTI will make it possible for city halls to be able to estimate the number of trees on sidewalks and enable qualitative studies.
\end{abstract}

Keywords: Urban forestry; MUTI; Green infrastructure; Forest inventory; City Hall.

Recebido em 17.11.2020 e aceito em 12.04.2021

1 Engenheiro Florestal e Licenciado em Ciências Agrárias. Especialista em Marketing e em Agronegócios. Doutorando em Ciências Florestais. Escola Superior de Agricultura "Luiz de Queiroz" (ESALQ), Universidade de São Paulo (USP). Piracicaba/SP. E-mail: friquemendes@usp.br 


\section{INTRODUÇÃO}

Novas estimativas apontam a existência de três trilhões de árvores no mundo, na qual praticamente metade concentra-se em áreas tropicais e subtropicais, com destaque para a bacia amazônica que, sozinha, abriga cerca de 400 bilhões de exemplares, sendo uma das principais responsáveis pelos ciclos biogeoquímicos da Terra. Ao considerar uma população mundial de 7,2 bilhões de pessoas, tem-se uma relação de 422 árvores por pessoa, equivalendo a sete vezes mais do que acreditava ser no passado (CROWTHER et al., 2015).

Em termos de sustentabilidade, a arborização urbana, por sua vez, pode ter maior percepção pelas pessoas devido ao contato mais direto no dia a dia, desempenhando importantes funções econômicas, sociais e ambientais, com ao menos 22 benefícios, tais como valorização dos espaços adjacentes, melhoria da saúde mental das pessoas, regulação climática, filtragem de poluentes, sombreamento etc. (BURDEN, 2006; SOARES et al., 2011; MCPHERSON et al., 2017; RAYMUNDO et al., 2020). Entretanto, a arborização viária frequentemente esbarra em dificuldades de implantação por exigir manutenção minuciosa e monitoramento constante, estando sujeitas a potenciais danos, como sujeira com folhas (e consequente entupimento de calhas), conflitos com fiação elétrica e, mais crítico, queda de galhos e árvores inteiras, capazes de causar acidentes trágicos (ESCOBEDO; KROEGER; WAGNER, 2011; MENDES; OLIVEIRA, 2019). Dessa forma, o inventário das árvores urbanas aparece como uma ferramenta imprescindível para o planejamento do verde, conforme feito por Mendes et al. (2015) no campus da ESALQ/USP, em Piracicaba, estado de São Paulo, Brasil, analisando tecnicamente quase cinco mil árvores para fins de manejo.

Por questões financeiras, burocráticas, logísticas e de tempo, as poucas prefeituras que possuem inventário arbóreo ou realizaram amostragem (para posterior extrapolação) ou são cidades pequenas, geralmente com até 50 mil habitantes, o que torna o trabalho mais factível. Logo, é comum que muitas prefeituras não saibam quantas árvores têm em seu perímetro urbano. Sendo esse dado fundamental para o planejamento da infraestrutura verde, a Secretaria do Meio Ambiente do estado de São Paulo lançou, em 2007, o Programa Município VerdeAzul (PMVA), que corresponde a um conjunto de diretivas relacionadas à gestão ambiental, dentre as quais a arborização urbana, com intuito de estimular o desenvolvimento de políticas públicas sustentáveis no estado, na qual os municípios mais bem classificados têm prioridades na captação de recursos financeiros, além de, claro, promover melhorias ambientais aos munícipes criando cidades mais resilientes (PMVA, 2020).

Algumas prefeituras no Brasil adotam políticas públicas que incentivam abatimentos no Imposto Predial e Territorial Urbano (IPTU), criando o chamado IPTU Verde, o qual concede descontos neste imposto para quem possuir árvores em sua calçada ou áreas impermeáveis no 
quintal. Araraquara/SP, São Carlos/SP, Americana/SP, Curitiba/PR e Vila Velha/ES são alguns exemplos de municípios que adotam o IPTU Verde, embora haja algumas divergências relacionadas à metodologia de análise de cada município (CUNHA; MARTINEZ; NOSSA, 2013).

Tendo em vista as incertezas das estimativas de quantas árvores existem nas cidades, 0 objetivo desta pesquisa foi desenvolver um modelo estatístico capaz de suprir esta necessidade, ou seja, estimar a quantidade de árvores nas ruas das cidades, analisando, em complementação, o manejo da arborização urbana adotado pelas prefeituras.

\section{MATERIAL E MÉTODOS}

A metodologia foi qualiquantitativa e consistiu em quatro partes: respectivamente, ajuste do modelo estatístico, investigação da taxa de arborização urbana das cidades paulistas, estudo de caso da cidade de São Paulo e análise do manejo da arborização urbana pelas prefeituras paulistas.

Para o ajuste do modelo estatístico fez-se um levantamento bibliográfico de cidades do estado de São Paulo que possuíam inventário da arborização urbana, como Piracicaba, Sorocaba, Campinas, São Paulo, Santo Antônio da Alegria, lacanga, São Simão e Águas de São Pedro, compondo cidades de pequeno, médio e grande porte. Esses documentos, comumente sob domínio das prefeituras, ficam disponíveis na forma de trabalhos técnicos, circulares, notícias de mídia, artigos científicos e, às vezes, em banco de dados. A quantidade de árvores urbanas foi cruzada com a população de cada cidade, sendo esta estimada pelo Instituto Brasileiro de Geografia e Estatística (IBGE), tomando-se a base 1000 habitantes para obter números inteiros, ou seja, a quantidade de árvores urbanas dividida 1000 habitantes (árv/1000 hab.), criando, assim, o "Índice Mendes de Arborização Urbana" (IMAU) - "Mendes Urban Tree Index" (MUTI), em inglês, ou "Índice Mendes de Arborización Urbana” (IMAU), em espanhol sendo definido como a taxa de arborização urbana baseada na população da cidade, representado por faixas quantitativas e qualitativas. Ele é composto por quatro faixas comparativas para que avalie se a quantidade de árvores viárias é satisfatória ou crítica, dada uma determinada população humana. Esse índice representa, assim, o primeiro parâmetro qualiquantitativo para iniciar a avaliação da arborização viária. Uma vez estimados os parâmetros quantitativos pelo modelo estatístico, estes poderão ser utilizados em cidades que não têm inventário, ou seja, bastará saber sua população para ter uma ideia de quantas árvores ela possui. Como há diferentes arquiteturas urbanas existentes no Brasil e no mundo, ou seja, desenhos urbanos e realidades distintas (NERY; SOUZA; ADORNO, 2019), este estudo pioneiro limitou-se ao estado de São Paulo, de modo a reduzir as incertezas das estimativas. 
O estado de São Paulo possui uma população estimada de 46 milhões de pessoas, representando pouco mais de $20 \%$ da população brasileira, distribuídos em 645 municípios dentre os 5570 existentes (12\% do total), apresentando Índice de Desenvolvimento Humano (IDH) de 0,783, o segundo melhor do país atrás apenas do Distrito Federal. Quanto aos biomas, estão presentes a Mata Atlântica, situada próxima ao litoral, e o Cerrado, na porção centro-oeste (IBGE, 2020). As taxas de arborização dos 645 municípios foram extraídas do IBGE, referentes ao ano de 2010. O geoprocessamento foi realizado no software QGIS versão 2.18, criando, inicialmente, um código identificador (ID) para cada município do estado, em ordem alfabética, o qual foi automatizado por meio da Calculadora de Campo ( $\$ \mathrm{id}+1$, posto que o primeiro ID é 0 ) para que, na sequência, com a ferramenta Uniões ("Join"), fosse realizada a correta junção do município com a respectiva taxa de arborização urbana, baseado num campo em comum (no caso, ID). Esse procedimento economizou tempo à medida que não foi necessário digitar a taxa de arborização para cada município.

Foi feito estudo de caso na cidade de São Paulo/SP, representando a aplicabilidade do IMAU nas 32 subprefeituras da capital e suas cinco regiões administrativas (norte, sul, leste, oeste e centro). Resultados do último censo indicaram uma população de 11.253.503 pessoas para a cidade de São Paulo (IBGE, 2020), com estimativa de pouco mais de 652 mil árvores no sistema viário, excluindo parques e áreas verdes, conforme metodologia adotada pela Emplasa, a partir de ortofotos (GEOSAMPA, 2014).

Por fim, a análise do manejo da arborização urbana pelas prefeituras foi feita entre os anos de 2019 e 2020, com visitas a campo para observações in loco em cidades do interior (Bariri, Guatapará e Piracicaba) e litoral (Caraguatatuba), a fim de abordar a correta gestão das árvores urbanas, servindo como suporte aos gestores ambientais e tomadores de decisão, visto que os casos encontrados são comuns a muitas prefeituras. Destaca-se que todos os nomes científicos utilizados nesta pesquisa foram atualizados conforme o site oficial Flora do Brasil 2020.

\section{RESULTADOS E DISCUSSÃO}

O modelo estatístico considerou cidades com inventários amostrais ou totais, tais como Piracicaba, Sorocaba, Campinas, São Paulo, Santo Antônio da Alegria, lacanga, São Simão e Águas de São Pedro. Ambos possuem vantagens e limitações. O primeiro caracteriza-se por realizar uma amostragem (sendo elas aleatórias ou estratificadas baseado em alguma regra, como classe social ou a distribuição dos quarteirões, por exemplo) dentro da área de interesse e depois extrapolar para todo o perímetro urbano. É economicamente mais atrativo devido aos 
menores custos envolvidos, possibilitando uma primeira impressão da arborização urbana, na qual Rollo (2014) recomenda 10\% dos quarteirões que perfazem os limites urbanos da cidade. Entretanto, tem como limitação a possibilidade de erros na extrapolação e, claro, a não avaliação de todas as árvores urbanas quanto ao risco de queda, dada a heterogeneidade na distribuição quanto ao espaço e às espécies. O segundo, por sua vez, também conhecido por censo arbóreo ou inventário $100 \%$, refere-se ao levantamento de toda a área, não permitindo erros estatísticos, porém, tem um custo elevado, já que demanda mais tempo de serviço em campo e escritório para o processamento dos dados. Por meio de uma correlação linear obteve-se a equação y = 17,44x - 413.389, sendo y a quantidade de habitantes e x a quantidade de árvores, uma variável dependente da outra (Figura 1). Em outras palavras, pode-se dizer que o modelo estima uma média de 7 habitantes para cada árvore existente (mediana igual a 6 hab./árvore ou 172 árv/1000 hab.). A recomendação é tomar como base a mediana perante a média uma vez que a esta evita que valores extremos mascarem a realidade.

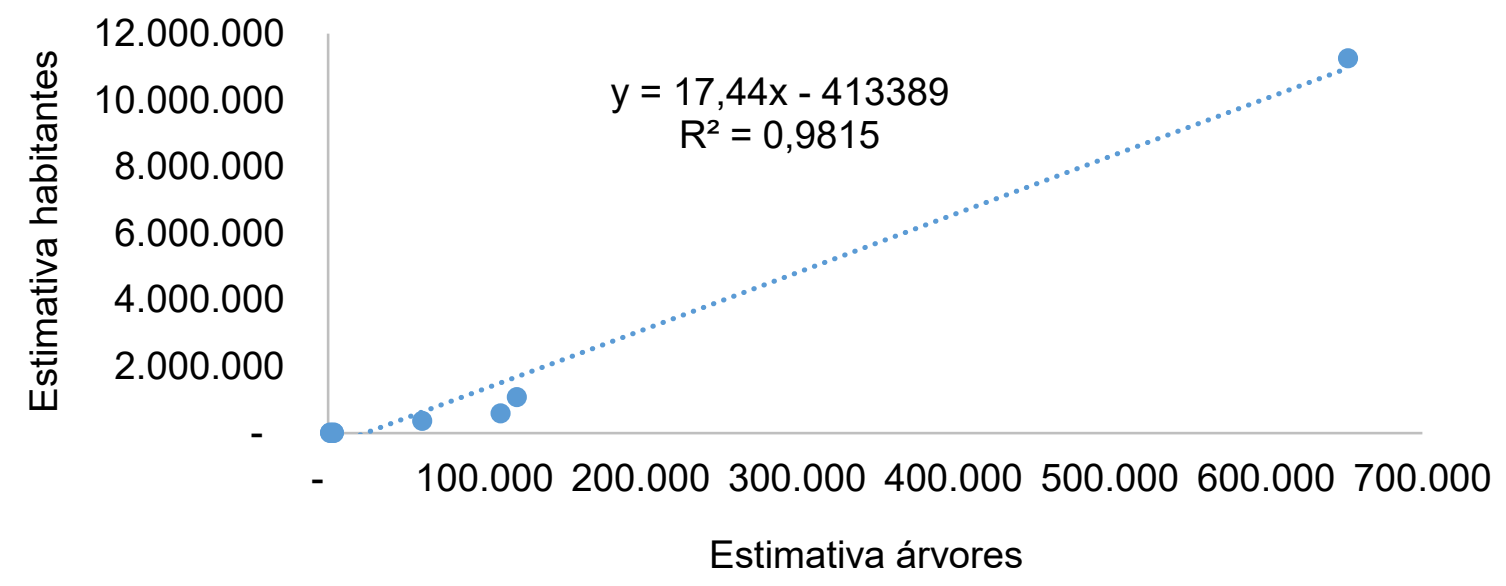

Figura 1. Modelo preditivo da quantidade de árvores baseado na população da cidade Figure 1. Predictive model of the number of trees based on the population of the city

A recomendação mínima de área verde sugerida pela Sociedade Brasileira de Arborização Urbana (SBAU, 1996) é de $15 \mathrm{~m}^{2} / \mathrm{hab}$. Adotando que uma árvore de grande porte tenha $5 \mathrm{~m}$ de raio ( $\varnothing$ igual a $10 \mathrm{~m}$ ), esta possuirá $75 \mathrm{~m}^{2}$ de copa, logo, uma proporção de 1:5, ou seja, uma árvore a cada 5 habitantes (ou 200 árvores a cada 1000 hab.). O IMAU considera indivíduos provenientes somente da arborização viária, desconsiderando-se parques e praças públicas por estes serem muito heterogêneos quanto à distribuição entre as cidades, não tendo o parâmetro "calçada" para tomar como base, cujo valor acima de 200 árv/1000 hab. (equivalente a 0,2 árv/hab.) representa o valor ideal (Tabela 1), entretanto, cada caso deve ser analisado individualmente, pois pode haver cidades com poucas árvores nas calçadas, mas muitas áreas verdes. O uso da arborização viária e não parques para o IMAU garante, desta forma, melhor 
distribuição da infraestrutura verde na malha urbana e uma maior justiça ambiental à sociedade. Como comparação, a cidade brasileira exemplo é Maringá/PR, com IMAU estimado em 360 árv/1000 hab. (SAMPAIO; ANGELIS, 2008).

Tabela 1. Faixas quantitativas e qualitativas do IMAU

Table 1. Quantitative and qualitative ranges of MUTI

\begin{tabular}{lc}
\hline IMAU - Faixa quantitativa & IMAU - Faixa qualitativa \\
\hline Mais que 200 árv/1000 hab. & Muito satisfatório \\
Entre 175 e 199 árv/1000 hab. & Parcialmente satisfatório \\
Entre 150 e 174 árv/1000 hab. & Crítico \\
Abaixo de 150 árv/1000 hab. & Muito crítico \\
\hline
\end{tabular}

Em termos gerais, as cidades litorâneas apresentaram as menores taxas de arborização do estado, com destaque para a região do Vale do Ribeira, que é caracterizada por ser uma área pobre (em detrimento da conservação da Mata Atlântica, opondo-se ao desenvolvimento econômico, sendo esta uma questão polêmica). Por outro lado, as cidades mais a norte e oeste do estado (segundo quadrante), como as regiões de Presidente Prudente, Araçatuba, São José do Rio Preto, Ribeirão Preto, Araraquara, Assis e Marília constituem as mais arborizadas (Figura 2). Um fator capaz de explicar isso é o forte calor, com constantes temperaturas do ar acima de $30^{\circ} \mathrm{C}$, causando sensações de desconforto humano (GOMES; AMORIM, 2003; MENDES et al., 2019).

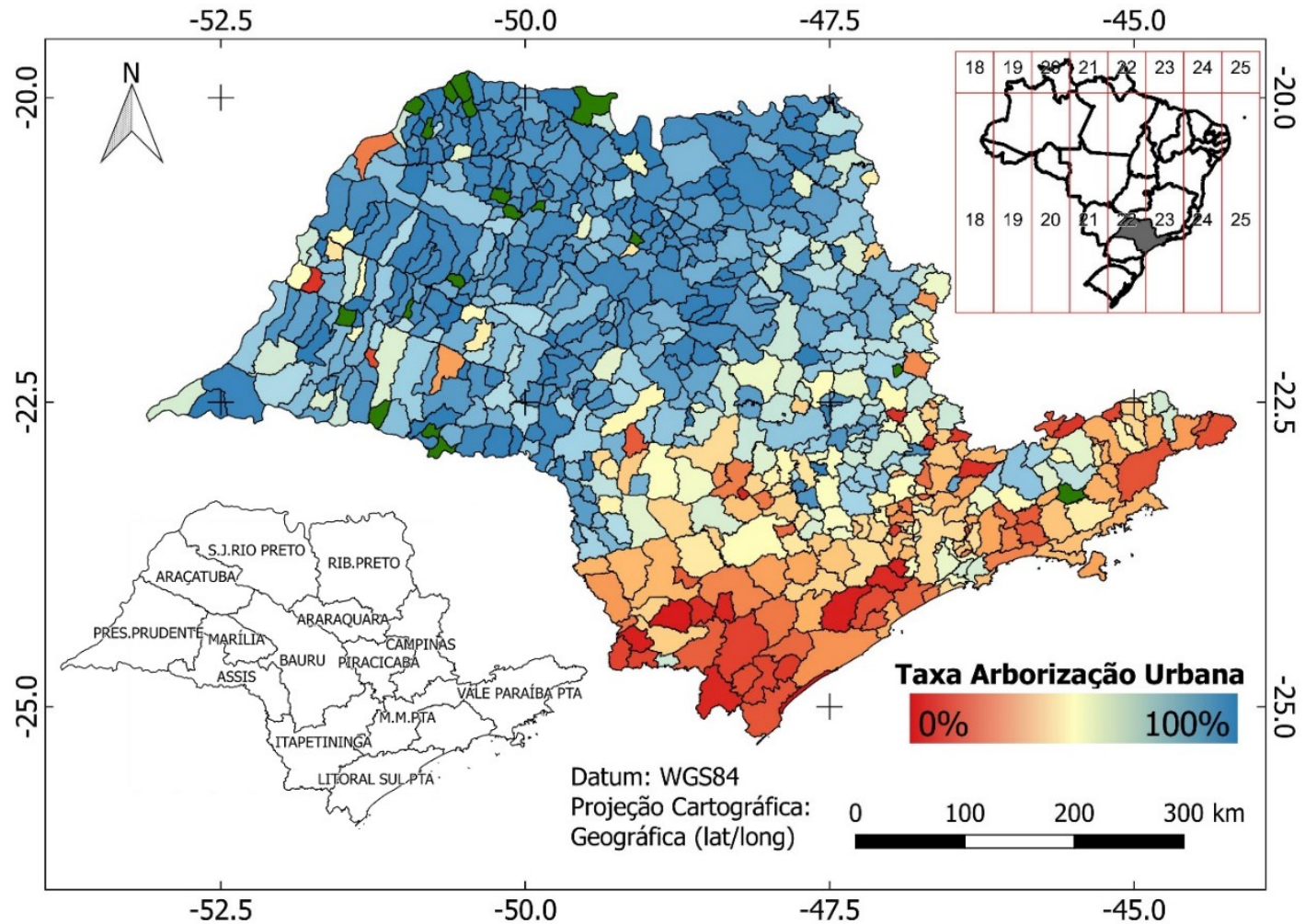

Figura 2. Taxa de arborização urbana das cidades do estado de São Paulo, a partir dos dados do IBGE Figure 2. Rate of the urban forest of cities in the State of São Paulo, based on IBGE data 
O valor médio da arborização viária das cidades do estado foi de $86,4 \%$, o desvio padrão de $17,9 \%$ e a mediana igual a $94,9 \%$, variando desde $1,7 \%$ em llha Comprida, $10,7 \%$ em Ribeirão Branco e 13,3\% em Miracatu até 18 cidades com 100\%. São Paulo, Guarulhos e Campinas, as três cidades mais populosas do estado, por exemplo, possuem 74,8\%, 71,2\% e 87,5\%, respectivamente. Porém, nessa análise da arborização realizada pelo IBGE foram considerados trechos urbanos com ao menos uma árvore na face da rua observada, o que pode representar limitação, uma vez que coloca no mesmo patamar cidade com apenas uma árvore na rua e outra cidade que apresenta, por exemplo, mais de 10 indivíduos em uma única rua, sendo necessário, assim, mais parâmetros metodológicos que avaliem também a espacialidade e a quantidade (MENDES et al., 2016).

Em São Paulo/SP, a Zona Oeste foi a que se destacou na arborização viária, sendo a subprefeitura de Pinheiros com o maior IMAU: 172,4 árv/1000 hab., seguido por Butantã $(114,9)$ e Lapa $(87,6)$. Santo Amaro $(165,8)$ e Vila Mariana $(94,8)$ na Zona Sul fecham as cinco melhores. Por outro lado, Cidade Tiradentes $(16,6)$ e Itaim Paulista $(26,2)$, ambos na Zona Leste, representaram os piores índices (Figura 3), ou seja, a diferença entre Pinheiros e Cidade Tiradentes chega à 10 vezes. A Zona Leste é uma região muito populosa e povoada, que detém quase $40 \%$ do total da população de São Paulo, necessitando de mais árvores urbanas, visto que possui apenas 44,4 árv/1000 hab., o menor IMAU das cinco regiões. O mais elevado foi a Zona Oeste $(123,1)$, seguido pela Zona Sul $(58,5)$, Norte $(52,6)$ e Centro $(52,4)$. A cidade de São Paulo, por sua vez, apresentou IMAU igual a 58,0, correspondendo a uma cidade com alto potencial de arborização viária, embora a elevada estimativa de mais de 650 mil árvores pareça ser suficiente. Buckeridge (2015) ressalta a importância da arborização viária da capital na umidificação do ambiente, comparando as árvores a rios voadores, capazes de transpirar 260 mil $\mathrm{m}^{3}$ diários, equivalente a um rio de $3 \mathrm{~m}^{3} \mathrm{~s}^{-1}$ de vazão, tomando como base a tipuana (Tipuana tipu (Benth.) Kuntze), espécie mais abundante em São Paulo/SP, plantada pela empresa inglesa City durante o planejamento de novos bairros no início do século XX. 


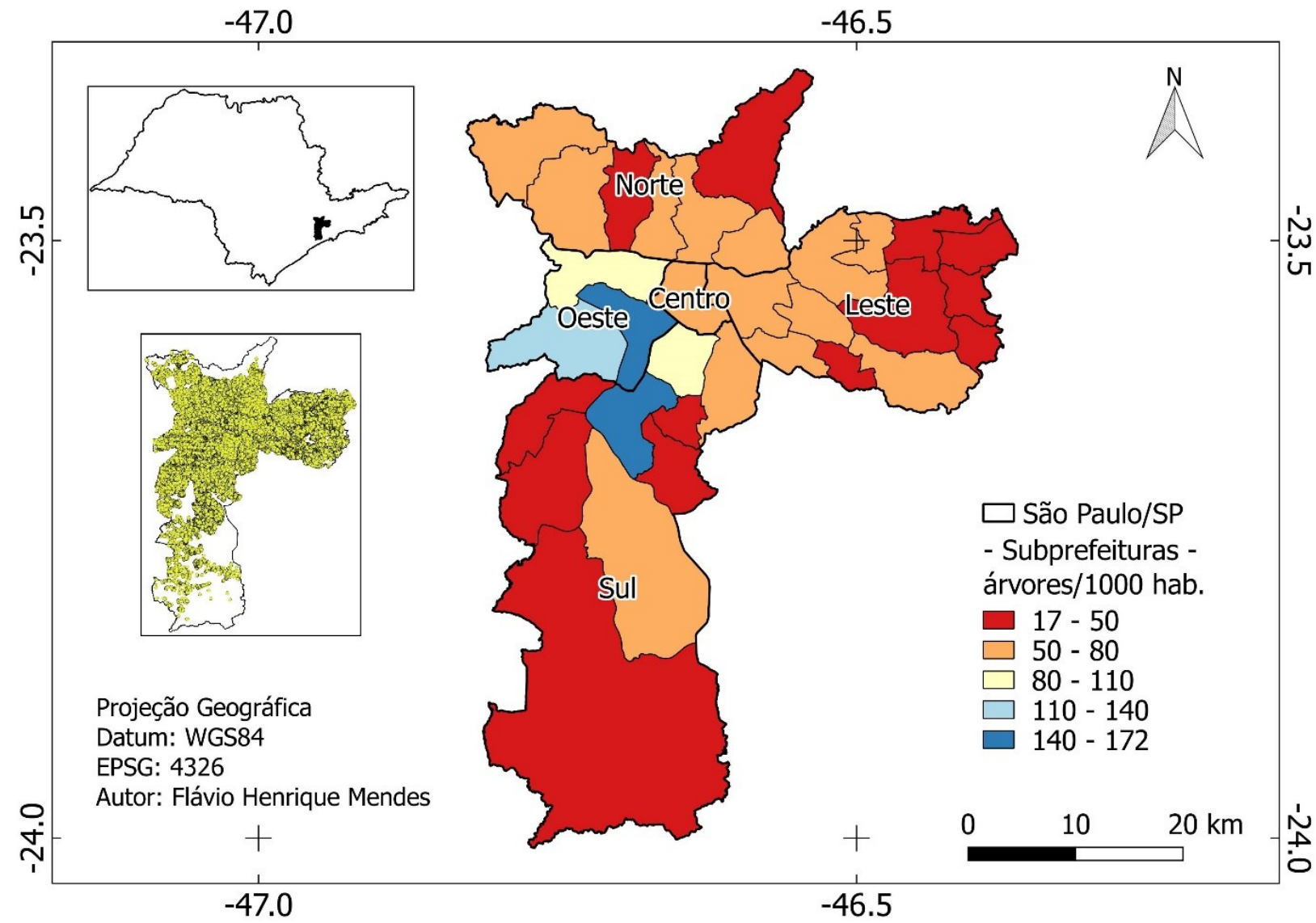

Figura 3. Quantidade de árvores a cada 1000 habitantes em São Paulo/SP, mostrando a localização do município no estado e a espacialização das 652 mil árvores viárias

Figure 3. Number of trees per 1000 inhabitants in São Paulo/SP, showing the location of the municipality in the State and the spatialization of the 652 thousand street trees

Uma vez obtidos os dados quantitativos, os próximos foram os dados qualitativos, referentes ao manejo. Identificação da espécie, localização, dimensões, conflitos com mobiliários urbanos, análise do canteiro, sanidade das raízes, colo, tronco e copa, necessidade de poda ou mesmo a substituição em caso de alto risco de queda são algumas das possíveis recomendações que devem ser feitas (MENDES et al., 2015). Muitas prefeituras brasileiras possuem dificuldades para a gestão da infraestrutura verde, em contraposição, grandes cidades dos EUA, como São Francisco/CA, Nova lorque/NY e Washington DC, são alguns exemplos que realizaram inventários participativos, na qual os munícipes auxiliam no cadastro por meio de uma plataforma on-line, afinal, são eles os protagonistas dos serviços ecossistêmicos (TRETHEWAY et al., 1999).

As cidades menores, sobretudo do interior do estado, são mais horizontalizadas. Dessa forma, elas tendem a ter mais árvores por habitantes do que os grandes centros urbanos verticalizados, como São Paulo e Campinas, cidades com mais de um milhão de habitantes, ou seja, uma relação inversa entre densidade populacional e quantidade de arborização urbana. Assim, outras variáveis como o tamanho da área urbana e a quilometragem de calçadas podem 
melhorar o modelo estatístico, embora o objetivo do IMAU seja obter uma rápida estimativa da quantidade de árvores. É comum ver no interior, principalmente no oeste paulista, um tipo de manejo característico: uso de poucas espécies que recebem podas de topiaria, com destaque para oiti (Licania tomentosa (Benth.) Fritsch), falsa-murta (Murraya paniculata (L.) Jack) e figueira-benjamim (Ficus benjamina L.), nesta ordem, todas espécies que se adaptam bem às podas e, devido aos potenciais problemas com fiação elétrica, acabam sendo rebaixadas de seus portes originais pela prefeitura ou pelo próprio morador. Comumente especialistas e leigos afirmam "árvore certa no lugar certo", porém, quando questionados sobre a recomendação de manejo ou indicação de ao menos cinco espécies para arborização urbana no Brasil, simplesmente citam os ipês (Handroanthus spp.) e nada mais, mostrando a complexidade do tema e a escassez de profissionais no ramo da arborização urbana. Por outro lado, é mais comum encontrar recomendações de quais espécies não devem ser utilizadas.

A ausência de diversidade genética de espécies torna a arborização mais susceptível a pragas e doenças, conforme alertado por Sadava et al. (2009) após o incidente com o olmo holandês (Ulmus americana L.) no leste dos EUA (Nova lorque, Detroit, Chicago, Mineápolis) na segunda metade do século XX, cujo carregamento de toras de madeira da Holanda veio contaminada com uma praga (fungo Ophiostoma ulmi (Buisman) Nannf., causador da grafiose, também conhecida por doença holandesa do ulmeiro, cujo vetor são escaravelhos da família Curculionidae que, quando larvas, se alimentam de tal fungo), causando a morte de mais de $75 \%$ da arborização urbana. Logo, sugere-se no máximo $10 \%$ da mesma espécie, porém, é interessante ruas temáticas nas cidades para facilitar a gestão e obter benefícios sensoriais únicos, como por exemplo as floradas. Algumas prefeituras utilizam manilha como delimitador de canteiro e outras costumam cimentar a base (colo), ambas com o intuito de evitar danos às calçadas, porém, não são procedimentos recomendados, visto que aquela pode promover o enovelamento de raízes e a consequente queda, e esta dificulta a respiração das raízes. Não obstante, a principal intervenção são as podas mal executadas, seja ela feita pela prefeitura, morador ou companhias elétricas, deixando os chamados tocos, os quais podem facilitar a entrada de patógenos, ou realizando podas drásticas, capazes de causar desequilíbrio biomecânico (Figura 4). 


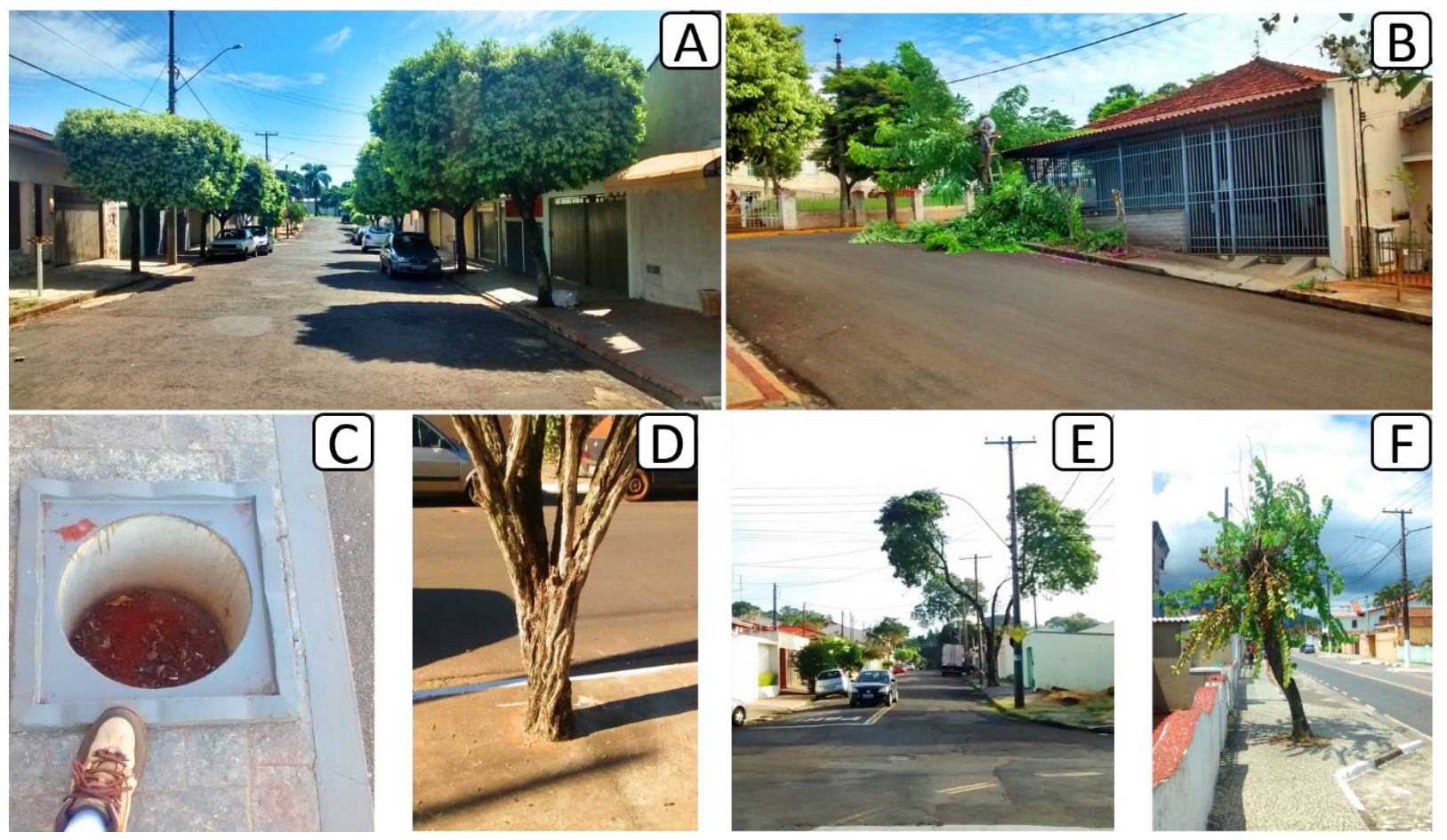

Figura 4. Respectivamente: A) abundância de oitis em Bariri, no Centro-Oeste paulista; B) chuva-de-ouro - Cassia fistula L. - sendo podada pelo morador em Bariri, deixando tocos; C) manilha em Bariri; (D) colo cimentado em Guatapará, no Nordeste paulista; E) sibipiruna - Poincianella pluviosa (DC.) L.P.Queiroz - com poda em V, em Piracicaba, no Centro-Sul do estado; F) pata-de-vaca Bauhinia sp. - com poda drástica em Caraguatatuba, no litoral

Figure 4. Respectively: A) abundance of oiti trees in Bariri, in the Midwest of São Paulo State; B) chuvade-ouro tree - Cassia fistula L. - being pruned by the resident in Bariri, leaving stumps; C) cylindrical tube in Bariri; (D) collar cemented in Guatapará, in the Northeast of São Paulo State; E) sibipiruna - Poincianella pluviosa (DC.) L.P.Queiroz - tree with V pruning, in Piracicaba, in the Center-South of the State; F) pata-de-vaca tree - Bauhinia sp. - with drastic pruning in Caraguatatuba, on the coast

Salienta-se que os casos apresentados na Figura 4 não se restringem apenas às cidades mencionadas, mas são facilmente encontrados em vários municípios, sendo os exemplos apenas ilustrativos. Outro fator de extrema importância ao planejamento é o melhor lado da rua para alocar a fiação elétrica, tendo em vista que este é um dos principais conflitos da arborização. Almejando-se a sombra nos períodos mais críticos do dia (à tarde) para mitigar o excesso de calor, recomenda-se que postes e fiação estejam na face sul ou leste (cidades do hemisfério sul), liberando mais espaço no lado oposto (norte e oeste) para que árvores de grande porte maximizem seus serviços ecossistêmicos, embora a fiação subterrânea seja a recomendada a longo prazo (VELASCO; LIMA; COUTO, 2006).

A Figura 5 mostra exemplos aplicados em que prefeitura e morador fizeram esforços para manter a árvore: preservação por meio de patrimônio histórico tombado de uma sapucaia (Lecythis pisonis Cambess.) centenária, plantada em 1918 para celebrar o fim da Primeira Guerra Mundial, estimada em $12 \mathrm{~m}$ de altura, 4,8 m de CAP (1,5 m de DAP) e $450 \mathrm{~m}^{2}$ de copa bem distribuída; preservação de raízes de ancoragem de um pau-ferro (Libidibia ferrea (Mart. ex Tul.) 
L.P.Queiroz) durante uma obra no campus da ESALQ; árvores para refrescar a sensação de conforto térmico num ponto de ônibus; esforço de um morador com fita isolante e grade para salvar a muda de um plátano (Platanus sp.) contra o vandalismo.

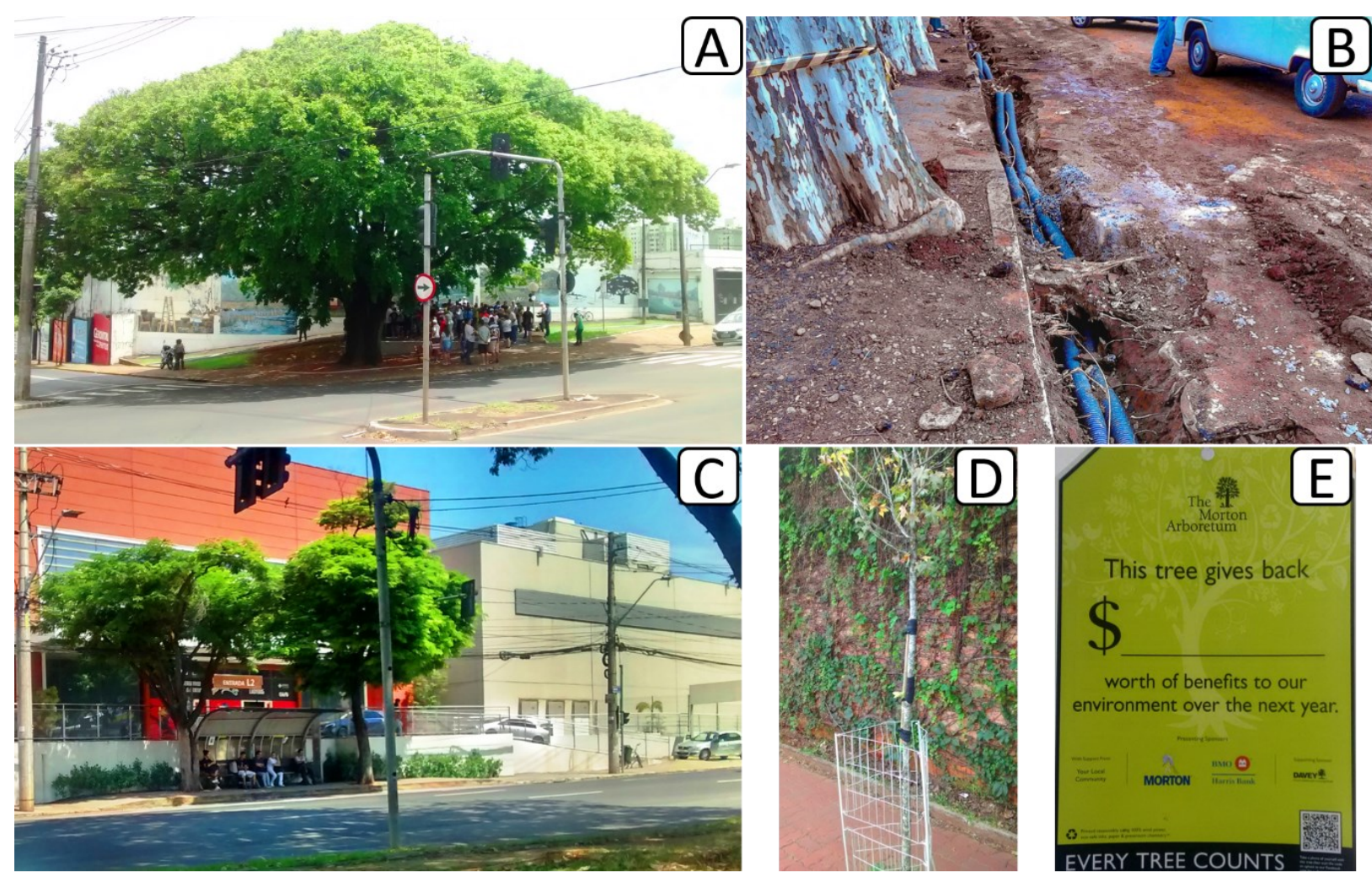

Figura 5. Todas registradas em Piracicaba/SP, respectivamente: A) espaço adequado para sapucaia centenária de 1918; B) preservação de raízes de pau-ferro; C) duas sibipirunas sombreando um ponto de ônibus em frente ao Shopping Piracicaba; (D) esforço de um morador com fita isolante e grade para salvar um plátano do vandalismo; E) exemplo de placa indicativa de quanto uma árvore retorna em serviços ecossistêmicos

Figure 5. All registered in Piracicaba, São Paulo State, respectively: A) adequate space for centenary sapucaia tree of 1918; B) preservation of pau-ferro tree roots; C) two sibipiruna trees shading a bus stop in front of Shopping Piracicaba; (D) a resident's effort with an adhesive tape and a grid to save a London plane tree from vandalism; E) example of a sign indicating how much a tree returns in ecosystem services

\section{CONCLUSÃO}

O modelo estatístico utilizado para criar o Índice Mendes de Arborização Urbana fornecerá ao menos uma rápida estimativa da quantidade de árvores existentes nas calçadas para que, na sequência, viabilizem estudos qualitativos, sendo o parâmetro de 172 árv/1000 hab. (equivalente a 6 hab./árv) o principal indicativo. Quanto à distribuição da arborização urbana no estado de São Paulo, está mais presente nas regiões oeste e norte, com mais árvores por habitante, evidenciando o benefício da sombra proporcionado pelas árvores, dado que o calor é muito forte nestas regiões. 


\section{AGRADECIMENTO}

O autor agradece à professora doutora Sônia Maria de Stefano Piedade, do Departamento de Ciências Exatas da ESALQ/USP, pela revisão estatística.

\section{REFERÊNCIAS}

BUCKERIDGE, M. Árvores urbanas em São Paulo: planejamento, economia e água. Estudos Avançados, São Paulo, v. 29, n. 84, p. 85-101, 2015.

BURDEN, D. Urban Street Trees: 22 Benefits Specific Applications. Orlando: Glatting Jackson and Walkable Communities Inc., 2006. 21p.

CROWTHER, T.W.; GLICK, H.B.; COVEY, K.R.; BETTIGOLE, C.; MAYNARD, D.S.; THOMAS, S.M.; SMITH, J.R.; HINTLER, G.; DUGUID, M.C.; AMATULLI, G.; TUANMU, M.N.; JETZ, W.; SALAS, C.; STAM, C.; PIOTTO, D.; TAVANI, R.; GREEN, S.; BRUCE, G.; WILLIAMS, S.J.; WISER, S.K.; HUBER, M.O.; HENGEVELD, G.M.; NABUURS, G.J.; TIKHONOVA, E.; BORCHARDT, P.; LI, C.F.; POWRIE, L.W.; FISCHER, M.; HEMP, A.; HOMEIER, J.; CHO, P.; VIBRANS, A.C.; UMUNAY, P.M.; PIAO, S.L.; ROWE, C.W.; ASHTON, M.S.; CRANE, P.R.; BRADFORD, M.A. Mapping tree density at a global scale. Nature, Berlin, v. 525, p. 201-205, 2015.

CUNHA, D.S.A.; MARTINEZ, A.L.; NOSSA, V. Incentivos fiscais verdes e tributação extrafiscal: estudo sobre o IPTU verde no município de Vila Velha (ES) comparativamente a outros municípios. Revista Razão Contábil \& Finanças, Fortaleza, v. 4, n. 1, p. 79-98, 2013.

ESCOBEDO, F.J.; KROEGER, T.; WAGNER, J.E. Urban forests and pollution mitigation: Analyzing ecosystem services and disservices. Environmental Pollution, Amsterdam, v. 159, n. 8-9, p. 2078-2087, 2011.

FLORA DO BRASIL 2020. Jardim Botânico do Rio de Janeiro. Disponível em: <http://floradobrasil.jbrj.gov.br/>. Acesso em: 16 mar. 2021.

GEOSAMPA. Mapa Digital da Cidade de São Paulo. 2014. Disponível em: http://geosampa.prefeitura.sp.gov.br/PaginasPublicas/_SBC.aspx>. Acesso em: 21 maio 2020.

GOMES, M.A.S.; AMORIM, M.C.C.T. Arborização e conforto térmico no espaço urbano: estudo de caso nas praças públicas de Presidente Prudente (SP). Caminhos de Geografia, Uberlândia, v. 7, n. 10, p. 94-106, 2003.

IBGE - INSTITUTO BRASILEIRO DE GEOGRAFIA E ESTATÍSTICA. Brasil / São Paulo. 2020. Disponível em: <https://cidades.ibge.gov.br/brasil/sp/panorama>. Acesso em: 07 fev. 2020.

MCPHERSON, E.G.; XIAO, Q.; DOORN, N.S.; GOEDE, J.; BJORKMAN, J.; HOLLANDER, A.; BOYNTON, R.M.; QUINN, J.F.; THORNE, J.H. The structure, function and value of urban forests in California communities. Urban Forestry \& Urban Greening, Amsterdam, v. 28, p. 4353, 2017.

MENDES, F.H.; OLIVA, G.T.; ARANTES, B.L.; ABREU, R.N.; CELLA, A.C.; POLIZEL, J.L.; SILVA FILHO, D.F. Diversidade arbórea e análise estrutural em jardim inglês da Universidade de São Paulo. Ciência e Natura, Santa Maria, v. 37, n. 3, p. 220-231, 2015. 
MENDES, F.H.; PETEAN, F.C.S.; POLIZEL, J.L.; SILVA FILHO, D.F. Avaliação da fragmentação da cobertura arbórea de Maringá/PR utilizando geotecnologias. Scientia Plena, São Cristóvão, v. 12, n. 9, p. 1-9, 2016.

MENDES, F.H.; OLIVEIRA, R.L.Z. Percepção da arborização urbana por estudantes de marketing. South American Development Society Journal, São Paulo, v. 5, n. 14, p. 189205, 2019.

MENDES, F.H.; PIEDADE, S.M.S.; MENDES, L.G.; LOPES, A.M.S.; SILVA FILHO, D.F. Probabilidade de ocorrência de altas temperaturas do ar e chuvas intensas em Piracicaba/SP. Geografia em Atos, Presidente Prudente, v. 1, n. 9, p. 51-65, 2019.

NERY, M.B.; SOUZA, A.A.L.; ADORNO, S. Os padrões urbano-demográficos da capital paulista. Estudos Avançados, São Paulo, v. 33, n. 97, p. 5-36, 2019.

PMVA - PROGRAMA MUNICÍPIO VERDEAZUL. O Programa. 2020. Disponível em: $<$ https://www.infraestruturameioambiente.sp.gov.br/verdeazuldigital/>. Acesso em: 06 fev. 2020.

RAYMUNDO, E.P.B.; BIONDI, D.; DACÓL, F.V.; LEAL, M.S.; REKSIDLER, K. Efeitos microclimáticos de um fragmento de floresta urbana em Curitiba-PR. Revista da Sociedade Brasileira de Arborização Urbana, Curitiba, v. 15, n. 3, p. 18-27, 2020.

ROLLO, L.C.P. Metodologias de quantificação de áreas verdes urbanas: mapeamento da cobertura arbórea e inventário florestal de árvores de rua em cidades do Estado de São Paulo. Piracicaba, 2014. 103f. Tese (Doutorado em Recursos Florestais) - Escola Superior de Agricultura Luiz de Queiroz, Universidade de São Paulo, Piracicaba, 2014.

SADAVA, D.; HELLER, H.C.; ORIANS, G.H.; PURVES, W.K.; HILLIS, D.M. Vida: A Ciência da Biologia - Volume 2. Evolução, Diversidade e Ecologia. 8.ed. Porto Alegre: Artmed, 2009. 448p.

SAMPAIO, A.C.F.; ANGELIS, B.L.D. Inventário e análise da arborização de vias públicas de Maringá-PR. Revista da Sociedade Brasileira de Arborização Urbana, Piracicaba, v. 3, n. 2, p. 37-57, 2008.

SOARES, A.L.; REGO, F.C.; MCPHERSON, E.G.; SIMPSON, J.R.; PEPER, P.J.; XIAO, Q. Benefits and costs of street trees in Lisbon, Portugal. Urban Forestry \& Urban Greening, Amsterdam, v. 10, n. 2, p. 69-78, 2011.

SOCIEDADE BRASILEIRA DE ARBORIZAÇÃO URBANA (SBAU). Carta a Londrina e Ibiporã. Boletim Informativo, Piracicaba, v. 3, n. 5, p. 1-3, 1996.

TRETHEWAY, R.; SIMON, M.; MCPHERSON, E.G.; MATHIS, S. Volunteer-based urban forest inventory and monitoring programs. Sacramento: US Forest Service, 1999. 27p.

VELASCO, G.D.N.; LIMA, A.M.L.P.; COUTO, H.T.Z.D. Análise comparativa dos custos de diferentes redes de distribuição de energia elétrica no contexto da arborização urbana. Revista Árvore, Viçosa, v. 30, n. 4, p. 679-686, 2006. 